\title{
Evaluation of mean platelet volume in localized scleroderma*
}

\author{
Anil Gulsel Bahali ${ }^{1}$ \\ Nazan Emiroglu ${ }^{1}$ \\ Mehmet Onur Kaya ${ }^{2}$
}

\author{
Ozlem Su${ }^{1}$ \\ Fatma Pelin Cengiz ${ }^{1}$ \\ Nahide Onsun ${ }^{1}$
}

DOI: http:/ /dx.doi.org/10.1590/abd1806-4841.20176045

\begin{abstract}
BACKGROUND: Localized scleroderma is a chronic inflammatory skin disease characterized by sclerosis of the dermis and subcutaneous tissue. Platelets play an important role in inflammation. Following activation, platelets rapidly release numerous mediators and cytokines, which contribute to inflammation.

ОвјестіVEs: To evaluate whether there was any relation between localized scleroderma and platelet parameters.

METHODS: Forty-one patients with localized scleroderma were enrolled in the study. The control group consisted of 30 healthy subjects.

RESULTS: The mean platelet volume level in the patient group was $9.9 \pm 1.3 \mathrm{fl}$ and in the control group was $7.6 \pm 1.1 \mathrm{fl}$. This difference was statistically significant $(\mathrm{p}<0.001)$. The plateletcrit values are minimally higher in the patient group as compared to the control group. It was statistically significant $(\mathrm{p}<0.001)$. There was no significant difference in the platelet counts between the two groups $(p=0.560)$ In the patient group, there was no significant relation between the mean platelet volume levels and clinical signs of disease $(p=0.09)$. However, plateletcrit values are higher in generalized than localized forms of disease $(p=0.01)$. StUdy Limitations: The limited number of patients and the retrospective nature of the study were our limitations.

ConCLusions: This study suggests that platelets might play a role in the pathogenesis of scleroderma. Platelet parameters may be used as markers for evaluating disease severity and inflammatory processes. Thus, there is a need for more detailed and prospective studies.
\end{abstract}

Keywords: Blood platelets; Scleroderma, localized; Transforming growth factor beta

\section{INTRODUCTION}

Localized scleroderma (LS), also known as morphea, is an idiopathic, chronic inflammatory skin disease characterized by sclerosis of the dermis and subcutaneous tissue without internal involvement. It is a rare disease and is more common in women. The woman to man ratio is 2-3 to 1 . The etiopathogenesis of morphea has not yet been fully understood. However, vascular injury, activated $\mathrm{T}$ cells, and increased production of collagen play a role in the pathogenesis of the disease. ${ }^{1-3}$

Platelets (PLT) play an important role in inflammation and in innate and adaptive immunity in addition to their role in hemostasis, thrombosis, and tissue repair. ${ }^{4,5}$ Following activation, platelets rapidly release numerous mediators and cytokines, which contribute to inflammation. Recently, several studies have reported that platelets are involved in the pathogenesis of some cutaneous inflammatory diseases such as atopic dermatitis, psoriasis, and contact dermatitis. ${ }^{6}$ Plateletcrit (PCT) and mean platelet volume (MPV) are platelet parameters that reflect platelet activation and function. MPV has frequently been used as an inflammatory marker in various diseases associated with inflammation. ${ }^{7-9}$
Although there have been studies on MPV and its relation with many diseases, its role in LS remains unclear. In this study, we compared platelet parameter levels between patients with LS and healthy controls.

\section{METHODS}

Forty-one patients who were diagnosed with LS at our outpatient clinic and followed regularly from January 2013 to September 2015 were enrolled in the study. Diagnosis was confirmed by skin biopsy and clinical findings. Thirty healthy controls were also included. Age, gender, values of MPV and PCT, and platelet counts were collected retrospectively from records. Furthermore, patients and healthy controls who had received any medicine affecting platelet function (e.g., acetyl salicylate, antiepileptics, heparin, etc.) and had a concomitant disease - such as other chronic inflammatory diseases (e.g., rheumatoid arthritis [RA] and inflammatory bowel disease), hypertension, diabetes mellitus, cardiovascular disorders, cancer, chronic infectious diseases, hematological diseases, chronic liver or kidney diseases, and autoimmune and neurologic disorders

$\overline{\text { Received on 10.05.2016. }}$

Approved by the Advisory Board and accepted for publication on 22.06.2016.

* Study conducted at the Department of Dermatology, Medical Faculty, Bezmialem Vakif University - Istanbul, Turkey.

Financial support: None.

Conflict of interest: None.

Department of Dermatology, Bezmialem Vakıf University - Istanbul,Turkey.

Department of Biostatistics, BezmialemVakıf University - Istanbul, Turkey.

C2017 by Anais Brasileiros de Dermatologia 
- were excluded from our study. Cell-Dyn 3700 (Abbott Diagnostics, UK) automated analyzer was used to conduct complete blood counts. Reference range for MPV was between 7.0 and $11 \mathrm{fl}$. Patients were categorized according to the following clinical features: en coup de sabre, generalized LS, or circumscribed LS.

\section{Statistical analysis}

Descriptive statistics were presented for normally distributed variables as mean \pm SD and were presented for not normally distributed variables as a median (minimum - maximum). Percentage and count were used for categorical data. Furthermore, distribution of variables was examined by the Shapiro Wilk test. An independent sample t-test was used for statistical comparison of data that matched normal distribution. Mann-Whitney U-test was also used to compare variables between groups when data was not distributed normally. Finally, statistical analyses were conducted using IBM SPSS version 20.0 , with a $p$ value $<0.05$ considered to be statistically significant.

\section{RESULTS}

Forty-one patients with LS were enrolled in the study. Thirty-one were women, and 10 were men. Patients' ages ranged between 12 and 68 years (mean age 44.1). Control group was composed of 30 patients ( 8 men and 22 women) aged between 11 and 69 years (mean age 40.0). Among the patients included in the study, two had en coup de sabre, 18 patients had circumscribed LS, and 20 patients had generalized LS.

Mean MPV levels in the patient group were $9.9 \pm 1.3 \mathrm{fl}$ and in the control group were $7.6 \pm 1.1 \mathrm{fl}$. MPV values were found to be higher in the LS group, and this difference between control group and patients was statistically significant $(p<0.001)$. Mean PCT counts were minimally higher in the patient group when compared with the control group, and it was statistically significant. There was no significant difference in PLT counts between the two groups (Table 1).

In the patient group, there was no significant relation between mean MPV levels and clinical signs of disease $(p=0.09)$. However, PCT values were higher in generalized when compared with localized forms of the disease $(\mathrm{p}=0.01)$.

\section{DISCUSSION}

Scleroderma is a chronic connective tissue disease that is characterized by inflammatory, vascular, and sclerotic changes.

TABLE 1: Comparison of demographic and laboratory characteristics of the patients and control groups

\begin{tabular}{lccc} 
& $\begin{array}{c}\text { Patients group } \\
(\mathrm{n}: 41)\end{array}$ & $\begin{array}{c}\text { Control group } \\
(\mathrm{n}: 30)\end{array}$ & $p$ \\
\hline Age (mean) & $44.1 \pm 17.6$ & $40.0 \pm 18.0$ & \\
\hline $\begin{array}{l}\text { Gender } \\
\text { (women/men) }\end{array}$ & $31 / 10$ & $22 / 8$ & \\
PCT $^{\mathrm{a}}$ & $0.2 \pm 0.07$ & $0.2 \pm 0.05$ & $<0.001^{*}$ \\
${\mathrm{PLT}\left(/ \mathrm{mm}^{3}\right)^{\mathrm{a}}}_{\mathrm{MPV}(\mathrm{fl})^{\mathrm{a}}}$ & $267.76 \pm 65.2$ & $259.67 \pm 44.3$ & 0.560 \\
\hline
\end{tabular}

$\mathrm{MPV}$; mean platelet volume, PLT; platelet, PCT; plateletcrit; ${ }^{*} \mathrm{p}<0.05$; ${ }^{\text {a Values are }}$ presented as mean $\pm \mathrm{SD}$
This disease is divided into two groups: systemic sclerosis (SS) and LS. SS is characterized by internal involvement in addition to skin findings. However, extracutaneous involvement is rarely observed in LS. Some authors have nonetheless reported that extracutaneous manifestations in morphea are not rare. In fact, most of the authors reported that these diseases are similar because both of them share common inflammatory and immunologic pathways. Development of morphea is associated with multiple triggering factors such as trauma/radiation, medications, infection, autoimmunity, and microchimerism. The pathogenesis of LS has not yet been completely understood. Both of these diseases are pathologically defined by an increase in collagen and extracellular matrix deposition. In pathogenesis, the initial change is vascular endothelial injury, and this injury increases the expression of adhesion molecules. These adhesion molecules facilitate the recruitment of T lymphocytes. Inflammatory cells increase the production of profibrotic cytokines. ${ }^{13,10,11}$ There have been studies that investigated on the role of several cytokines and mediators in the pathogenesis of scleroderma. One of these is transforming growth factor-beta (TGF- $\beta$ ), which plays an important role in tissue fibrosis by stimulating fibroblasts to increase the production of extracellular matrix proteins. TGF- $\beta$ has an inhibitor effect on extracellular matrix breakdown, and Higley et al. reported that serum levels of TGF- $\beta$ increased in LS patients. ${ }^{2,4,12,13}$

In the literature, several studies have demonstrated that platelets play an important role in the pathophysiology of some skin diseases such as regulating inflammation, inducing fibrosis, and provoking pruritus. ${ }^{6,14,15}$ The role of platelets in SS has been known but not completely. ${ }^{4,16}$ Under normal physiological conditions, platelets do not interact with non-activated endothelium. Following endothelial injury, endothelial cells express adhesion molecules that mediate platelet rolling. ${ }^{6}$ After that, activated platelets release various cytokines, hormones (such as TGF- $\beta$ ), and platelet-derived growth factor (PDGF). These molecules contribute to the vascular, immunological, and connective tissue pathology of scleroderma. ${ }^{4,17}$

To our knowledge, there is no study in the literature that investigates the relation between LS and MPV. In this study, we found that MPV and PCT levels were higher in the patient group when compared with healthy subjects. We did not find a significant relation between MPV and the extent of the disease, but there was a positive correlation with PCT values. There are few studies in the literature that investigated the role of platelets in SS. Soydinç et al. reported that MPV levels were elevated in 76 patients with SS, which is similar to our results. In addition, they reported that MPV levels were negatively correlated with disease activity score. ${ }^{5}$ Finally, Hirigoyen et al. evaluated platelets and secreted molecules for 30 SS patients and found that TGF- $\beta$ levels were significantly higher in platelet releasates from patients when compared with the control group. ${ }^{4}$

High MPV values show either increased platelet activation and function or increased numbers of large, hyperaggregable platelets. ${ }^{5}$ These large platelets have a greater mass, and they are both metabolically and enzymatically more active than smaller platelets. TGF- $\beta$ and PDGF, which play an important role in the pathogenesis of LS, are secreted from activated platelets. ${ }^{17,18}$ In our opinion, this mechanism might be one of those involved in the pathogenesis of scleroderma. 


\section{CONCLUSION}

In summary, MPV levels were higher in our patient group. In fact, the increased MPV levels support the role of platelets in the pathogenesis of LS. However, further studies are needed to fully understand the role of platelets in the pathogenesis of LS and their relation to disease severity. The limitations of our study were small number of patients and its retrospective nature. As a result of studies, platelet parameters may be used as markers for evaluating disease severity, inflammatory processes, or treatment plans.]

\section{REFERENCES}

1. Sartori-Valinotti JC, Tollefson MM, Reed AM. Updates on morphea: role of vascular injury and advances in treatment. Autoimmune Dis. 2013;2013:467808.

2. Valančienè $G$, Jasaitienè $D$, Valiukevičienè $S$. Pathogenesis and treatment modalities of localized scleroderma. Medicina (Kaunas). 2010;46:649-56.

3. Fett N, Werth VP. Update on morphea: part I. Epidemiology, clinical presentation, and pathogenesis. J Am Acad Dermatol. 2011;64:217-28.

4. Hirigoyen D, Burgos PI, Mezzano V, Duran J, Barrientos M, Saez CG, et al. Inhibition of angiogenesis by platelets in systemic sclerosis patients. Arthritis Res Ther. 2015;17:332.

5. Soydinc S, Turkbeyler IH, Pehlivan Y, Soylu G, Goktepe MF, Bilici M, et al. Mean platelet volume seems to be a valuable marker in patients with systemic sclerosis. Inflammation. 2014;37:100-6.

6. Tamagawa-Mineoka R. Important roles of platelets as immune cells in the skin. J Dermatol Sci. 2015;77:93-101.

7. Mahdavi-Zafarghandi R, Shakiba B, Keramati MR, Tavakkoli M. Platelet volume indices in patients with varicocele. Clin Exp Reprod Med. 2014;41:92-5.

8. Gasparyan AY, Ayvazyan L, Mikhailidis DP, Kitas GD. Mean platelet volume: a link between thrombosis and inflammation? Curr Pharm Des. 2011;17:47-58.

9. Oncel M, Kiyici A, Oncel M, Sunam GS, Sahin E, Adam B. Evaluation of Platelet Indices in Lung Cancer Patients. Asian Pac J Cancer Prev. 2015;16:7599-602.

10. Gorkiewicz-Petkow A, Kalinska-Bienias A. Systemic involvement in localized scleroderma/morphea. Clin Dermatol. 2015;33:556-62.

11. Careta MF, Romiti R. Localized scleroderma: clinical spectrum and therapeutic update. An Bras Dermatol. 2015;90:62-73.

12. Asano $\mathrm{Y}, \mathrm{Ihn} \mathrm{H}$, Jinnin M, Mimura Y, Tamaki K. Involvement of alphavbeta5 integrin in the establishment of autocrine TGF-beta signaling in dermal fibroblasts derived from localized scleroderma. J Invest Dermatol. 2006;126:1761-9.

13. Higley $\mathrm{H}$, Persichitte $\mathrm{K}$, Chu S, Waegell W, Vancheeswaran R, Black C. Immunocytochemical localization and serologic detection of transforming growth factor beta 1. Association with type I procollagen and inflammatory cell markers in diffuse and limited systemic sclerosis, morphea, and Raynaud's phenomenon. Arthritis Rheum. 1994;37:278-88.
14. Katoh N. Platelets as versatile regulators of cutaneous inflammation J Dermatol Sci. 2009;53:89-95.

15. Postlethwaite AE, Chiang TM. Platelet contributions to the pathogenesis of systemic sclerosis. Curr Opin Rheumatol. 2007;19:574-9.

16. Kahaleh MB, Osborn I, Leroy EC. Elevated levels of circulating platelet aggregates and beta-thromboglobulin in scleroderma. Ann Intern Med. 1982;96:610-3.

17. Coelho-Macias V, Mendes-Bastos P, Assis-Pacheco F, Cardoso J. Imatinib: a nove treatment approach for generalized morphea. Int J Dermatol. 2014;53:1299-302.

18. van der Loo B, Martin JF. A role for changes in platelet production in the cause of acute coronary syndromes. Arterioscler Thromb Vasc Biol. 1999;19:672-9.

\author{
MAILING ADDRESS: \\ Anil Gulsel Bahali \\ Department of Dermatology, \\ Medical Faculty, Bezmialem Vakif University, \\ 34093 Fatih, \\ Istanbul, Turkey. \\ E-mail:anilirli@yahoo.com
}

How to cite this article: Bahali AG, Su O, Emiroglu N, Cengiz FP, Kaya MO, Onsun N. Evaluation of mean platelet volume in localized scleroderma. An Bras Dermatol. 2017;92(5):635-7. 